\title{
Assessment of pupillary influence in LASIK patients using a digital pupillometer and VQF 25 questionnaire
}

\author{
Avaliação da influência pupilar em pacientes submetidos a LASIK com a utilização de um \\ pupilômetro digital e do questionário VQF 25
}

Eduardo Marcelo Moron de Andrade ${ }^{1}$, Wallace Chamon $^{1}$

\begin{abstract}
Purpose: Identify ideal profiles in patients undergoing to photorefractive laser surgery with the aid of an automated pupillometry and psychometric analysis of patients with visual function questionnaire (VQF 25).

Methods: Seventy-seven patients undergoing photorefractive laser surgery laser (LASIK) were analyzed with the aid of an automated digital pupillometer based on an infrared camera coupled to the optical head of a videokeratography system. Patients underwent complete ophthalmic evaluation and documentation of the pupillary behavior under different intensities of illumination, simulating situations of everyday life. Visual quality function questionnaire, translated to Portuguese was assessed.

Results: All patients, regardless of pupillary change under varying conditions of illumination (scotopic, mesopic and photopic) showed improvement in all sub-groups of the VQF 25. Pupil diameter was not the primary determinant of patients' visual satisfaction.

Conclusion: Despite digital pupillometer has proven to be a useful tool in documenting and understanding of pupil behavior, a set of factors such as psycho-social profile, preoperative ametropy and final residual ametropy, contributed decisively to determine the degree of satisfaction of patients undergoing LASIK.
\end{abstract}

Keywords: Pupil; Pupillary reflex; Corneal topography; Lasik; Questionnaire

\section{RESUMO}

Objetivo: Identificar perfis ideais em pacientes submetidos à cirurgia fotorrefrativa a laser com o auxílio de um pupilômetro automatizado e análise psicométrica de pacientes com o questionário de função visual (VQF 25).

Métodos: Setenta e sete pacientes submetidos à cirurgia fotorrefrativa a laser (LASIK) foram analisados com o auxílio de um pupilômetro digital automatizado baseado em uma câmera de infravermelho acoplado à cabeça óptica de um sistema de videoceratografia. Os pacientes foram submetidos à avaliação oftalmológica completae documentação do comportamento pupilar em diferentes intensidades de iluminação, simulando situações da vida cotidiana. O questionário de qualidade da função visual, traduzido para o Português, foi avaliado.

Resultados: Todosospacientes, independentementedamudançapupilarem diferentes condições de iluminação (escotópica, mesópica efotópica) apresentaram melhora em todos os subgrupos do VQF 25. O diâmetro pupilar não foi o principal determinante da satisfação visual dos pacientes.

Conclusão: Apesar do pupilômetro digital ter provado ser uma ferramenta útil na documentação e compreensão do comportamento da pupila, um conjunto de fatores, tais como o perfil psicossocial, ametropia pré-operatória e ametropia residual final, contribuiu de forma decisiva para determinar o grau de satisfação dos pacientes submetidos a LASIK.

Descritores: Pupila; Reflexo pupilar; Topografia da cornea; Ceratomileuse assistida por excimer laser; LASIK; Questionário

\section{INTRODUCTION}

The actual pupil importance on the final visual outcome of patients who underwent refractive surgery has not always been completely understood by refractive surgeons. Despite the fact that most patients that underwent refractive procedures achieved excellent uncorrected visual acuity, some may complain of visual symptoms under specific circumstances, especially in low-light environments ${ }^{(1)}$.

There is no doubt about the physical importance of the pupillary diameter in the final optical outcome after the refractive surgery, nevertheless preoperative clinical assessment still lacks in an appropriate pupil evaluation. The increase in higher order aberrations may lead to changes of contrast sensitivity and visual acuity degradation, often observed after laser surgeries. Several studies described a significant decrease of low contrast sensitivity under mesopic conditions after laser refractive procedures, despite of normal contrast sensitivity in photopic conditions in these patients ${ }^{(2,3)}$.
The subjective feature of the final visual acuity reveals the need to seek for a tool that may assist surgeons in the assessment of surgical outcomes. One of these forms is to use psychometric tests under the form of questionnaires to assess different aspects of visual function according to the pre-existing pathology.

This study aims to understand the influence of pupillary diameter in patients that underwent photorefractive keratectomy through LASIK by means of an automated capture system of pupillary diameter and psychometric analysis of patients with the visual function questionnaire VQF $25^{(4)}$.

\section{METHODS}

\section{ETHICS AND INFORMATION TO PATIENTS}

The Institutional Review Board of UNIFESP approved the research protocol with no restrictions. All patients agreed and signed the Informed Consent Form after being verbally informed about the study. 


\section{Ophthalmic evaluation}

All patients underwent a complete ophthalmic exam that included spectacle-corrected visual acuity (VA), corneal topography, manifest refraction, biomicroscopy, tonometry and cycloplegic refraction, 30 minutes after instillation of the second drop of cyclopentolate in both eyes $(\mathrm{OU})$ and central cornea ultrasound pachymetry. Pupillometry was evaluated as described below.

After orientation, it was requested to all patients to answer the VQF 25 questionnaire, translated to Portuguese, based on their current vision with the best correction available (glasses or contact lenses).

All screened patients were myopic and were operated with the same technique and by the same surgeon with an excimer laser Nidek model EC 5000 (Nidek ${ }^{\mathrm{TM}}$, Japan), after a flap creation with microkeratome Moria M2 model (Moria'M , France). The treatment zone used was standardized to $6 \mathrm{~mm}$ with a transition zone of $7.4 \mathrm{~mm}$. Following surgery, patients were instructed to use dexamethasone and tobramycin eye drops QID for 15 days. Artificial tears were prescribed 6 times a day for 30 days.

Follow-up visits were scheduled for postoperative days 1, 30, 90 and 180, with 15-day tolerance before or after the scheduled date. In all of these visits, except for day 1, a complete ophthalmic exam, including cycloplegic refraction, as well as corneal topography were performed. A new questionnaire VQF 25 was presented to the patient at each follow-up visit to be answered based on the current status of his/her vision.

\section{INCLUSION AND EXCLUSION CRITERIA}

It was enrolled in the study group myopic patients, who volunteered sought the Centro Capixaba de Olhos (CCO) in order to perform the correction of their ametropy (myopia, myopic astigmatism or mixed astigmatism). Only patients who presented normal ophthalmologic and preoperative topographies were included in this study. All patients presented stable refraction for at least 1 year, based on their prior prescriptions.

Patients with hyperopia, eye diseases, prior ocular surgery, decompensated systemic diseases and patients with variable refraction in the last year.

Only data from right eye was considered.

\section{Videokeratography SYSTEM CHARACTERISTICS}

It was used a prototype of a computed videokeratography Eyetec ${ }^{\circledast}$ CT 2000 (Eyetec Equipamentos Oftálmicos Ind. Com. Ltda, São CarIOS, SP, Brazil). This videokeratography unit incorporates an infrared camera for detecting the pupillary margin and 4 LEDs that emit light with visible wavelength. These LEDs provide light stimulation with time intervals, intensity and duration predetermined by the examiner while other 4 LEDs provide infrared light, allowing the documentation of pupillary behavior even under minimal lighting conditions. The pupillary data are managed and analyzed by a specific computer program, which provides a map of the pupillary closure curve under different light intensities.

Before starting the pupillometry, the lighting of the examination room was reduced to a standardized minimum level of lighting, and the patient was asked to keep their eyes open and looking at the central fixation point in the cone center and should not blink for about 10 seconds. The light stimulation were graded with predetermined duration of 1000 milliseconds and started with the lowest lighting (1 lux), with subsequent increases to 20 and 40 lux. Three measurements were performed for each eye, being used to produce the smoothest closing curve (Figure 1).

\section{VQF 25 APPLICATION METHOD}

After explanation of the test purpose, the patients were asked to answer all questions based on their best vision (glasses or contact lenses) in several situations of day-to-day life (Table 1).

Each question has received a score previously set, to get an average score by the sum of points of all questions and divided by the number of questions answered. Thus, it was prevented that patients who do not perform a certain activity, such as driving, obtain a lower score. The sum value of the questions obtained in these cases, had always been divided by a smaller number of questions, therefore the blank answers have been eliminated.

This questionnaire was repeated in each one of the visits, except the $1^{\text {st }}$ postoperative day, always based on the patient's current vision, as a basis of assessing the psycho-social changes caused by laser photorefractive surgery.

\section{RESULTS}

Seventy-seven right-eyes of 77 patients, 32 male (41.6\%) and 45 female (58.4\%), were evaluated. Their age ranged from 19 to 51 years old (mean of 32.4 years old).

Spherical equivalent ranged from +0.62 D to -10.12 D. Although no statistical significance was detected, figure 2 denotes a trend in better 90-Day VQF scores in lower preoperative spherical equivalent.

In all VQF 25 scales, as well as on the overall scale, there was a statistically significant increase in scores after surgery, indicating an improvement in the quality of life in many aspects assessed by the questionnaire. The overall average score increased from 73.3 points on pre-surgery to 93.1 points on 180-day postoperative visit, and the scale mean score "VISION" went from 67.4 points to 87 points post-surgery. The scales on which were observed a higher gain in scores (range $>30$ points) were "ROUTINE" and "MENTAL". The lowest gain (range $<10$ points) was observed respectively in the scales "COLORS" and "HEALTH".

When analyzing the outcomes obtained from the use of the prototype of an automated pupillometry with infrared camera, it was observed high accuracy and reproducibility of measurements enabling the minimization of the influence of the examiner ${ }^{(5,6)}$.

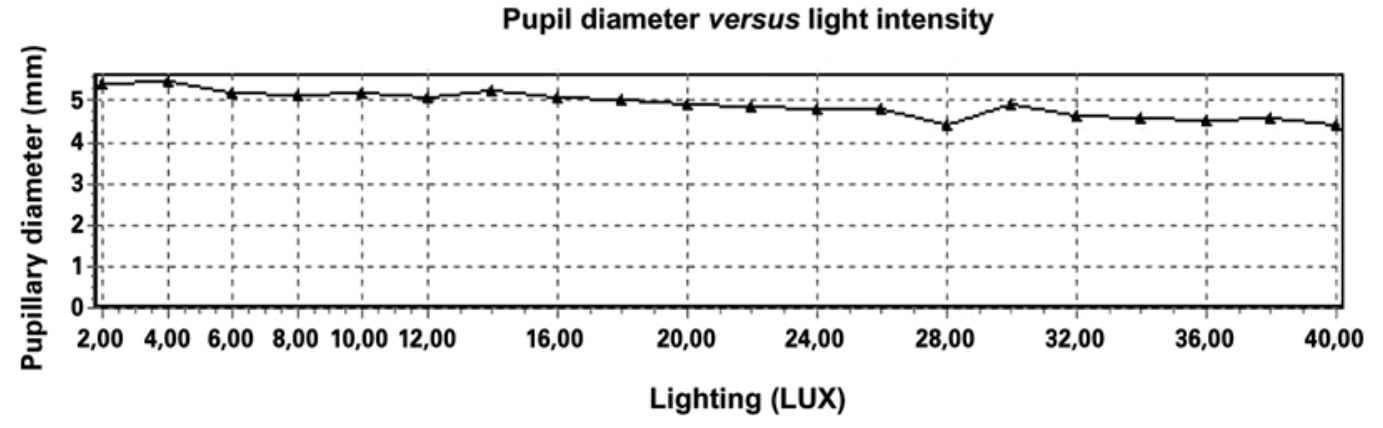

Figure 1. Pupillary closing curve for different light intensities. 
Table 1. Subdomains of the visual function questionnaire VQF 25

\begin{tabular}{lcc}
\hline Subdomain & Number of items & Questions \\
\hline General health & 1 & 1 \\
Vision & 1 & 2 \\
Ocular pain & 2 & 4,19 \\
Near sight activities & 3 & $5,6,7$ \\
Far sight activities & 3 & $8,9,14$ \\
Social activities & 2 & 11,13 \\
Mental health & 4 & $3,21,22,25$ \\
Daily life activities & 2 & 17,18 \\
Dependence & 3 & $20,23,24$ \\
Driving vehicles & 2 & 15,16 \\
Color vision & 1 & 12 \\
Peripheral vision & 1 & 10 \\
\hline
\end{tabular}

Source: Ferraz EV, Lima CA, Cella W, Arieta CE. Adaptação de questionário de avaliação da qualidade de vida para aplicação em portadores de catarata Arq Bras Oftalmol 2002:65(3):293-8.

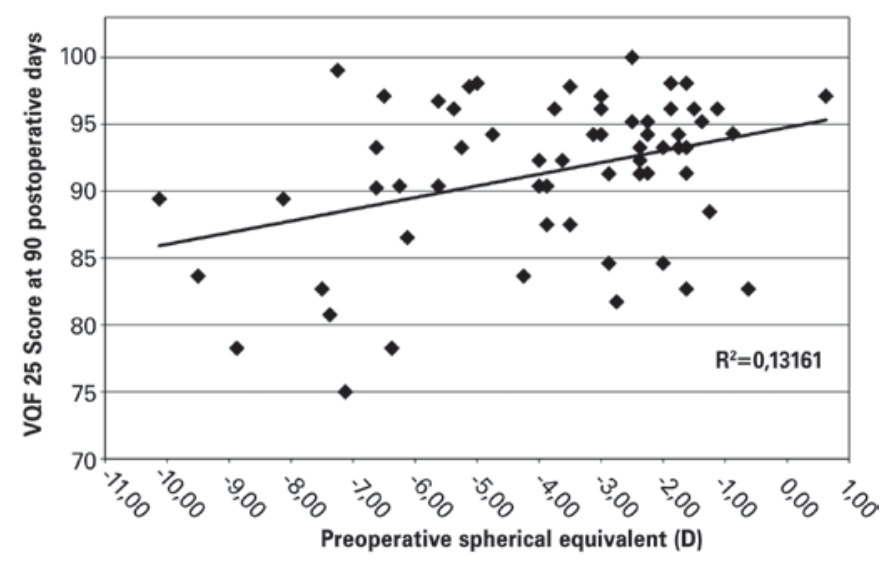

Figure 2. Relation between visual function questionnaire (VQF-25) scores at 90-day postoperative visit and preoperative spherical equivalent.

The pupillary diameter ranged between 3.0 and $6.0 \mathrm{~mm}$ (mean of $4.8 \mathrm{~mm}$ ) when the measurement had been performed under scotopic lighting conditions (1 Lux), between 2.4 and $6.0 \mathrm{~mm}$ (mean of $4.7 \mathrm{~mm}$ ) under mesopic lighting conditions (20 Lux) and between 2.8 and $5.9 \mathrm{~mm}$ (mean of $4.1 \mathrm{~mm}$ ) for maximum lighting condition (40 Lux).

When we correlate the pupillary diameter in the various subgroups of this study, we observed that the satisfaction degree and complaints varied according to the post-surgery period studied.

In patients evaluated after 30 days, the pupil size was statistically significant only for the subdomain "DEPENDENCE" with scotopic and mesopic pupil, i.e., in situations of medium and low lighting the patients felt limited although they have become independent from the use of optical aids (Table 2). In that same postoperative visit, they also reported visual upset and "PAIN" for environments with average lighting.

The same assessment performed at 90-day postoperative visit showed that the "PERIPHERAL VISION" presented a statistically significant relationship with mesopic pupil, i.e., there was some difficulty in noticing objects or people positioned laterally (Table 3). At 180-day postoperative visit, the subdomains "ROUTINE" and "DRIVING" showed statistically significant results only with photopic pupil, i.e., in good lighting environments, patients felt dissatisfied with their vision to perform their usual activities or driving (Table 4).

\section{DISCUSSION}

The visual outcomes in patients that underwent laser refractive surgery have always been evaluated by information provided by the own patient, in addition to clinical observations obtained by the surgeon on the post-surgery. In both cases the pupil role on the final outcome was questioned only in those cases where any post-surgery visual complaint was present and could not be explained despite of the final surgical outcome be considered satisfactory ${ }^{(7,8)}$.

Although the use of questionnaires to evaluate visual function and life quality quite common in ophthalmology worldwide, the use of a specific type of questionnaire trying to correlate the pupillary closure curve in patients underwent laser keratorefractive surgery have never been described in national literature ${ }^{(0,10)}$. We verified at all scales of VQF 25, as well as on the overall scale, a statistically significant increase in scores post-surgery, indicating an improvement on the life quality, in many aspects assessed by the questionnaire. The high outcome expectedness by the patient associated with fast visual recovery provided by LASIK, certainly contributes in a practical and psychological manner in increased self-esteem and sense of independence experienced by the patient. These factors could support the higher gain observed in the subdomain "MENTAL HEALTH".

It is worth mentioning the fact that the isolated use of the overall score of a questionnaire that evaluates multiple aspects of life quality should always be analyzed taking into account several subdomains, because the overall score may show higher increase, even if it has occurred a significant worsening in one or more scales. One of the critics that could be done regarding the overall scale of the VQF 25, for instance, consists in how your score is calculated, through the arithmetic mean of the scores for each subdomain, in which all have the same weight in the overall score. In fact, it must not expect that each aspect of life quality related to vision have the same importance for all patients underwent refractive surgery. The subdomain "DRIVING" will probably have higher relevance for a patient who needs to work as a professional driver than for a housewife, as well as the subdomain "MENTAL HEALTH" may have higher or lower importance according to the psychological aspects of each patient. It would be interesting to have a global scale calculated from a weighted average, in which each patient would attribute specific weights to the scales, according to their needs, activities, limitations and interests ${ }^{(11)}$.

In 2007 a similar study, where 97 patients underwent LASIK were assessed by VQF 25, was published. Statistical tests were used to calculate the scores among different subdomains of VQF 25 and some features like pupillary diameter and visual acuity without post-surgery correction were analyzed. Most of the patients reported being satisfied with their final vision, referring to their vision without correction were better and clearer than before. The authors concluded that the postoperative uncorrected visual acuity, but not the pupillary diameter, is the major factor in patient satisfaction after refractive surgery ${ }^{(12)}$.

\section{Pupil influence}

The pupil influence in the different sub-groups of this study, showed that the satisfaction level and complaints varied according to the studied postoperative visit. The complaints from patients under scotopic and mesopic conditions are most often related to physical symptoms such as pain ("PAIN") and difficulty in adapting to the new visual reality without correction ("DEPENDENCE") in the early stages of post-surgery. These symptoms can be explained by the fact that patients relate the success of their treatments not only for independence in the use of optical aids, but also by the absence of undesirable post-surgery signs such as pain, discomfort or sudden changes in vision ${ }^{(13)}$. 
Table 2. Correlation, at 30-day postoperative visit, among total scores and the subdomains of the questionnaire for assessment of visual function VQF 25 and pupillary diameters. Number of observations $=67$

\begin{tabular}{lcccccc}
\hline & $\begin{array}{c}\text { Pupil 0 } \\
\text { correlation coefficient }\end{array}$ & $\begin{array}{c}\mathbf{p} \\
\text { value }\end{array}$ & $\begin{array}{c}\text { Pupil 20 } \\
\text { correlation coefficient }\end{array}$ & $\begin{array}{c}\mathbf{p} \\
\text { value }\end{array}$ & $\begin{array}{c}\text { Pupil 40 } \\
\text { correlation coefficient }\end{array}$ & $\begin{array}{c}\mathbf{p} \\
\text { value }\end{array}$ \\
\hline Total score & 0.060 & 0.629 & 0.140 & 0.253 & 0.040 & 0.747 \\
Health & -0.182 & 0.140 & -0.114 & 0.358 & -0.174 & 0.160 \\
Vision & -0.300 & 0.810 & 0.001 & 0.996 & 0.041 & 0.743 \\
Pain & 0.101 & 0.416 & $0.257^{*}$ & 0.036 & 0.227 & 0.064 \\
Near sight activities & 0.175 & 0.157 & 0.167 & 0.177 & 0.501 & 0.688 \\
Far sight activities & -0.026 & 0.835 & -0.098 & 0.430 & -0.168 & 0.175 \\
Social activities & -0.016 & 0.900 & -0.032 & 0.796 & -0.139 & 0.263 \\
Mental health & 0.161 & 0.195 & 0.165 & 0.183 & 0.096 & 0.441 \\
Routine & -0.016 & 0.900 & 0.001 & 0.996 & 0.005 & 0.966 \\
Dependence & $0.242^{*}$ & 0.049 & $0.257^{*}$ & 0.035 & 0.194 & 0.117 \\
Driving & 0.014 & 0.913 & -0.101 & 0.418 & -0.123 & 0.322 \\
Colors & -0.182 & 0.140 & -0.029 & 0.817 & -0.115 & 0.355 \\
Peripheral vision & 0.057 & 0.646 & 0.039 & 0.753 & 0.016 & 0.897 \\
\hline
\end{tabular}

* Correlation is significant at level 0,05. Pupil $0=$ pupil diameter measured with 1 Lux; Pupil $20=$ pupil diameter measured with 20 Lux; Pupil $40=$ pupil diameter measured with 40 Lux.

Table 3. Correlation, at 90-day post-surgery, among total scores and the subdomains of the questionnaire for assessment of visual function VQF $\mathbf{2 5}$ and pupillary diameters. Number of observations $=62$

\begin{tabular}{|c|c|c|c|c|c|c|}
\hline & $\begin{array}{c}\text { Pupil } 0 \\
\text { correlation coefficient }\end{array}$ & $\begin{array}{c}\mathbf{p} \\
\text { value }\end{array}$ & $\begin{array}{c}\text { Pupil } 20 \\
\text { correlation coefficient }\end{array}$ & $\begin{array}{c}\mathbf{p} \\
\text { value }\end{array}$ & $\begin{array}{c}\text { Pupil } 40 \\
\text { correlation coefficient }\end{array}$ & $\begin{array}{c}p \\
\text { value }\end{array}$ \\
\hline Total score & 0.034 & 0.791 & 0.021 & 0.868 & 0.044 & 0.732 \\
\hline Health & -0.170 & 0.187 & -0.107 & 0.410 & -0.073 & 0.574 \\
\hline Vision & -0.070 & 0.588 & -0.013 & 0.923 & 0.002 & 0.986 \\
\hline Pain & 0.190 & 0.139 & 0.176 & 0.172 & 0.206 & 0.109 \\
\hline Near sight activities & 0.085 & 0.511 & 0.092 & 0.460 & 0.077 & 0.552 \\
\hline Far sight activities & -0.116 & 0.369 & -0.146 & 0.256 & -0.166 & 0.198 \\
\hline Social activities & -0.054 & 0.675 & -0.029 & 0.823 & -0.099 & 0.442 \\
\hline Mental health & 0.028 & 0.828 & -0.056 & 0.663 & -0.083 & 0.521 \\
\hline Routine & 0.048 & 0.709 & 0.085 & 0.513 & 0.133 & 0.303 \\
\hline Dependence & -0.078 & 0.544 & 0.012 & 0.927 & -0.011 & 0.930 \\
\hline Driving & 0.022 & 0.863 & -0.051 & 0.693 & 0.018 & 0.887 \\
\hline Colors & -0.038 & 0.769 & 0.141 & 0.273 & 0.029 & 0.820 \\
\hline Peripheral vision & -0.193 & 0.133 & $-0.289^{*}$ & 0.023 & -0.206 & 0.108 \\
\hline
\end{tabular}

* Correlation is significant at level 0,05. Pupil $0=$ pupil diameter measured with 1 Lux; Pupil 20= pupil diameter measured with 20 Lux; Pupil 40= pupil diameter measured with 40 Lux.

Daily activities such as work and driving ("ROUTINE" and "PERIPHERAL VISION") the complaints were often related to the pupils under photopic conditions and on prolonged post-surgery, which contradicts the expected, since one of the most frequent complaints of patients is exactly driving under scotopic conditions in the early stages. One possible explanation would be the fact that for some types of professional activity where the required visual level is pushed to the limit, minimum residual ametropies and post-surgery aberrations could be determinant to patient's complaints even under good lighting conditions ${ }^{(14)}$. The incidence of complaints under scotopic conditions is virtually absolute for all patients who underwent LASIK in the early stages of pre-surgery, tending to decrease or disappear over time. The pupillary diameter under low lighting, associated with the change in the cornea's natural asphericity after LASIK are directly involved in nocturne visual complaints ${ }^{(15-17)}$.

There is no consensus among researchers about what would be the boundary pupil diameter so that aberrations and residual ametropies would become a determining factor in visual degradation. According to some authors, this number would be around approximately $5.7 \mathrm{~mm}$, and may vary depending on the occupation of each individual, with no absolute relationship between pupil size and complaints on post-surgery ${ }^{(18)}$.

\section{Pupillometry}

The use of an automated pupillometry prototype linked to a videokeratographic unit allowed, not only, the correct reading of the 
Table 4. Correlation, at 180-day post-surgery, among total scores and the subdomains of the questionnaire for assessment of visual function VQF 25 and pupil diameters. Number of observations $=50$

\begin{tabular}{|c|c|c|c|c|c|c|}
\hline & $\begin{array}{c}\text { Pupil } 0 \\
\text { correlation coefficient }\end{array}$ & $\begin{array}{c}\mathbf{p} \\
\text { value }\end{array}$ & $\begin{array}{c}\text { Pupil } 20 \\
\text { correlation coefficient }\end{array}$ & $\begin{array}{c}\mathbf{p} \\
\text { value }\end{array}$ & $\begin{array}{c}\text { Pupil } 40 \\
\text { correlation coefficient }\end{array}$ & $\begin{array}{c}p \\
\text { value }\end{array}$ \\
\hline Total score & -0.087 & 0.549 & -0.141 & 0.329 & -0.041 & 0.780 \\
\hline Health & -0.159 & 0.269 & 0.083 & 0.566 & 0.147 & 0.308 \\
\hline Vision & -0.100 & 0.491 & -0.036 & 0.804 & 0.005 & 0.970 \\
\hline Pain & 0.158 & 0.273 & 0.262 & 0.066 & 0.172 & 0.232 \\
\hline Near sight activities & 0.034 & 0.815 & -0.033 & 0.820 & 0.007 & 0.960 \\
\hline Far sight activities & -0.134 & 0.352 & -0.230 & 0.108 & -0.177 & 0.218 \\
\hline Social activities & 0.026 & 0.859 & -0.091 & 0.528 & -0.133 & 0.357 \\
\hline Mental health & 0.065 & 0.652 & -0.100 & 0.491 & -0.019 & 0.895 \\
\hline Routine & 0.202 & 0.160 & 0.187 & 0.194 & $0.288^{*}$ & 0.043 \\
\hline Dependence & -0.227 & 0.112 & -0.125 & 0.387 & -0.128 & 0.375 \\
\hline Driving & 0.033 & 0.820 & 0.010 & 0.947 & $0.295^{*}$ & 0.510 \\
\hline Colors & -0.177 & 0.218 & -0.146 & 0.312 & -0.089 & 0.541 \\
\hline Peripheral vision & 0.111 & 0.444 & -0.042 & 0.772 & 0.006 & 0.965 \\
\hline
\end{tabular}

* Correlation is significant at level 0,05. Pupil $0=$ pupil diameter measured with 1 Lux; Pupil 20= pupil diameter measured with 20 Lux; Pupil $40=$ pupil diameter measured with 40 Lux.

pupillary diameter, as well as the variables of this diameter under scotopic, mesopic and photopic conditions. Thus, it was possible to observe through the graphic analysis the pupil closure curve and try to relate these outcomes with the patients, whom presented more post-surgery visual disorders. Despite providing a more comprehensive vision on pupillary behavior, we could not correlate the pupillary data with the answers provided by VQF 25 and ensure that the pupil size was the only or most important factor for postoperative visual satisfaction. The visual acuity and postoperative satisfaction of patients seem to be the outcome of the sum of several factors, including patient expectation, psycho-social profile, pupillary diameter and the final residual ametropy.

\section{CONCLUSIONS}

The questionnaire VQF 25 was helpful as a screening and followup tool in monitoring and evaluation of candidates to the keratorefractive surgery.

The pupillary analysis on variable conditions of lighting through an automated infrared system proved to be an accurate and reproducible method of pupillary evaluation, further allowing the dynamic documentation of pupillary movement. Nevertheless, pupillary diameter was not the only and predominant factor to predict what would be the ideal candidates to laser keratorefractive surgery.

\section{REFERENCES}

1. Martínez CE, Applegate RA, Klyce SD, McDonald MB, Medina JP, Howland HC. Effect of pupillary dilation on corneal optical aberrations after photorefractive keratectomy. Arch Ophthalmol. 1998;116(8):1053-62. Comment in Arch Ophthalmol. 1998;116(8): 1104-5.

2. Montés-Micó R, Charman WN. Mesopic contrast sensitivity function after excimer laser photorefractive keratectomy. J Refract Surg. 2002;18(1):9-13

3. Chalita MR, Krueger RR. Correlation of aberrations with visual acuity and symptoms. Ophthalmol Clin North Am. 2004;17(2):135-42, v-vi.
4. Belfort R, Campos M, Hoexter MQ, Belfort Júnior R, Mari JJ. O impacto da cirurgia de ceratectomia fotorrefrativa (PRK) e ceratomileuse assistida por excimer laser in situ (LASIK) na qualidade visual e de vida em pacientes com ametropias. Arq Bras Oftalmol. 2008;71(1):83-9.

5. Colvard M. Preoperative measurement of scotopic pupil dilation using an office pupillometer. J Cataract Refract Surg. 1998;24(12):1594-7.

6. Bradley JC, Anderson JE, Xu KT, Brown SM. Comparison of Colvard pupillometer and infrared digital photography for measurement of the dark-adapted pupil diameter. J Cataract Refract Surg. 2005;31(11):2129-32.

7. Netto MV, Ambrósio R Jr, Wilson SE. Pupil size in refractive surgery candidates. J Refract Surg. 2004:20(4):337-42. Comment in J Refract Surg. 2005:21(3):303.

8. Ferraz EV, Lima CA, Cella W, Arieta CE. Adaptação de questionário de avaliação da qualidade de vida para aplicação em portadores de catarata. Arq Bras Oftalmol. 2002; 65(3):293-8

9. Schallhorn SC, Kaupp SE, Tanzer DJ, Tidwell J, Laurent J, Bourque LB. Pupil size and quality of vision after LASIK. Ophthalmology. 2003;110(8):1606-14.

10. Nunes LM, Schor P. Avaliação do impacto da cirurgia refrativa na qualidade de vida por meio do questionário NEI-RQL (National Eye Institute Refractive Error Quality of Life). Arq Bras Oftalmol. 2005:68(6):789-96.

11. Schein OD. The measurement of patient-reported outcomes of refractive surgery: the refractive status and vision profile. Trans Am Ophthalmol Soc. 2000;98:439-69.

12. Schmidt GW, Yoon M, McGwin G, Lee PP, McLeod SD. Evaluation of the relationship between ablation diameter, pupil size, and visual function with vision-specific quality-of-life measures after laser in situ keratomileusis. Arch Ophthalmol. 2007;125(8): 1037-42. Comment in Arch Ophthalmol. 2008;126(4):584.

13. O'Doherty M, Kirwan C, O'Keeffe M, O'Doherty J. Postoperative pain following epi-LASIK, LASEK, and PRK for myopia. J Refract Surg. 2007:23(2):133-8.

14. Periman LM, Ambrosio R Jr, Harrison DA, Wilson SE. Correlation of pupil sizes measu red with a mesopic infrared pupillometer and a photopic topographer. J Refract Surg. 2003;19(5):555-9. Comment in J Refract Surg. 2004;20(5):490; author reply 490.

15. Chalita MR, Xu M, Krueger RR. Correlation of aberrations with visual symptoms using wavefront analysis in eyes after laser in situ keratomileusis. J Refract Surg. 2003;19(6): S682-6.

16. Dupps WJ Jr, Roberts C. Effect of acute biomechanical changes on corneal curvature after photokeratectomy. J Refract Surg. 2001;17(6):658-69.

17. Wang Y, Zhao K, Jin Y, Niu Y, Zuo T. Changes of higher order aberration with various pupil sizes in the myopic eye. J. Refrac Surgery. 2003;19(2 Suppl):S270-4.

18. Reinstein DZ, Archer TJ, Couch D, Schroeder E, Wottke M. A new night vision disturbances parameter and contrast sensitivity as indicators of success in wavefrontguided enhancement. J Refract Surg. 2005;21(5):S535-40. 